\title{
Competition between inter- and intra-molecular hydrogen bonding: An infrared spectroscopic study of jet-cooled amino-ethanol and its dimer
}

Pierre Asselin, Bruno Madebène, Pascale Soulard, Robert Georges, Manuel Goubet, Thérèse R. Huet,

Olivier Pirali, and Anne Zehnacker-Rentien

Citation: J. Chem. Phys. 145, 224313 (2016); doi: 10.1063/1.4972016

View online: http://dx.doi.org/10.1063/1.4972016

View Table of Contents: http://aip.scitation.org/toc/jcp/145/22

Published by the American Institute of Physics

\section{Articles you may be interested in}

Infrared laser spectroscopy of the n-propyl and i-propyl radicals: Stretch-bend Fermi coupling in the alkyl $\mathrm{CH}$ stretch region

J. Chem. Phys. 145, 224304224304 (2016); 10.1063/1.4971239

Conformational analysis of ethyl-substituted Criegee intermediate by FTMW spectroscopy

J. Chem. Phys. 145, 224314224314 (2016); 10.1063/1.4972017

Deep tunneling in the unimolecular decay of $\mathrm{CH} 3 \mathrm{CHOO}$ Criegee intermediates to $\mathrm{OH}$ radical products

J. Chem. Phys. 145, 234308234308 (2016); 10.1063/1.4972015

Hydrogen bond breaking dynamics in the water pentamer: Terahertz VRT spectroscopy of a $20 \mu \mathrm{m}$ libration

J. Chem. Phys. 146, 014306014306 (2017); 10.1063/1.4973418

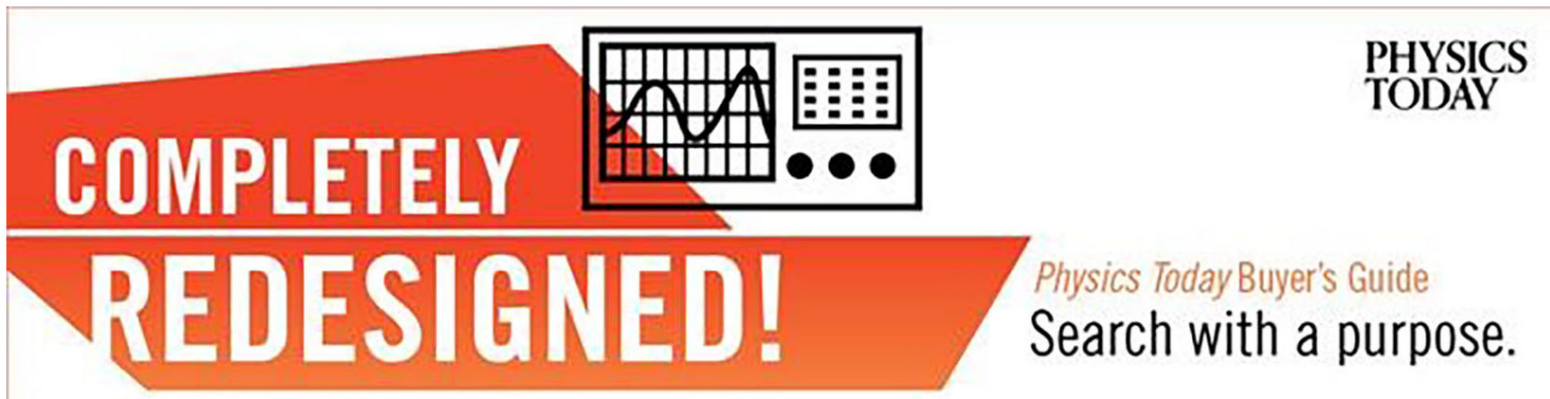




\title{
Competition between inter- and intra-molecular hydrogen bonding: An infrared spectroscopic study of jet-cooled amino-ethanol and its dimer
}

\author{
Pierre Asselin, ${ }^{1,2, a)}$ Bruno Madebène, ${ }^{1,2}$ Pascale Soulard, ${ }^{1,2}$ Robert Georges, ${ }^{3}$ \\ Manuel Goubet, ${ }^{4}$ Thérèse R. Huet, ${ }^{4}$ Olivier Pirali, ${ }^{5,6}$ and Anne Zehnacker-Rentien ${ }^{5}$ \\ ${ }^{1}$ Sorbonne Universités, UPMC Univ Paris 06, UMR 8233, MONARIS, F-75005 Paris, France \\ ${ }^{2}$ CNRS, UMR 8233, MONARIS, F-75005 Paris, France \\ ${ }^{3}$ Institut de Physique de Rennes, Campus de Beaulieu, Bat 11C, UMR 6251, Université de Rennes 1-CNRS, \\ 35042 Rennes Cedex, France \\ ${ }^{4}$ Université Lille, CNRS, UMR 8523-PhLAM-Physique des Lasers, Atomes et Molécules, F-59000 Lille, France \\ ${ }^{5}$ Institut des Sciences Moléculaires d'Orsay (ISMO), CNRS, University of Paris-Sud, Université Paris-Saclay, \\ F-91405 Orsay, France \\ ${ }^{6}$ Ligne AILES - Synchrotron SOLEIL, L'Orme des Merisiers, F-91192 Gif-sur-Yvette Cedex, France
}

(Received 21 September 2016; accepted 28 November 2016; published online 15 December 2016)

\begin{abstract}
The Fourier transform IR vibrational spectra of amino-ethanol (AE) and its dimer have been recorded at room temperature and under jet-cooled conditions over the far and mid infrared ranges $\left(50-4000 \mathrm{~cm}^{-1}\right)$ using the White-type cell and the supersonic jet of the Jet-AILES apparatus at the synchrotron facility SOLEIL. Assignment of the monomer experimental frequencies has been derived from anharmonic frequencies calculated at a hybrid CCSD(T)-F12/MP2 level. Various thermodynamical effects in the supersonic expansion conditions including molar dilution of $\mathrm{AE}$ and nature of carrier gas have been used to promote or not the formation of dimers. Four vibrational modes of the observed dimer have been unambiguously assigned using mode-specific scaling factors deduced from the ratio between experimental and computed frequencies for the monomer. The most stable $\mathrm{g}^{\prime} \mathrm{Gg}^{\prime}$ monomer undergoes strong deformation upon dimerization, leading to a homochiral head to head dimer involving two strong hydrogen bonds. Published by AIP Publishing. [http://dx.doi.org/10.1063/1.4972016]
\end{abstract}

\section{INTRODUCTION}

Hydrogen bonding plays a major role in defining the organization of matter, at both molecular and supramolecular levels, with effects ranging from the structuration of liquids to the shape of biomolecules. ${ }^{1}$ Of special interest is the intramolecular hydrogen bond, in which the donor and acceptor parts belong to the same entity. They tune the biomolecules' folding patterns and the way in which they interact with each other or with the solvent. In smaller systems as well, intramolecular hydrogen bonding has important structural consequences. Among them, the amino-alcohol motif has attracted particular interest due to its ubiquity in many life-related systems such as neurotransmitters or drug design. ${ }^{2}$ For example, the presence or absence of a hydrogen bond in 3-aminobutan-2ol, which depends on the stereochemistry of the hydroxyl and amino-bearing carbons, dictates the solid or liquid state of the molecule at room temperature. In larger systems as well, the presence or absence of an intramolecular $\mathrm{OH} \cdots \mathrm{N}$ hydrogen bond has important consequences in biological processes, which has prompted the study of numerous neurotransmitters based on the amino alcohol motif in the gas phase..$^{3,4}$

Unless strong steric constraints are imposed by bulky substituents or cyclic structure, ${ }^{5-7}$ the most stable structure of 1,2 amino-alcohols isolated in the gas phase or in a van der Waals matrix displays an intramolecular $\mathrm{OH} \cdots \mathrm{N}$ hydrogen

a)Email: pierre.asselin@upmc.fr bond. Depending on the strength of this hydrogen bond and on the environment, other conformations, either open or involving an $\mathrm{NH} \cdots \mathrm{O}$ interaction, may be observed. ${ }^{8}$ In particular, the intramolecular H-bond is disrupted in the bulk where intermolecular H-bonds, in which both nitrogen and oxygen can act as acceptors, are predominant. ${ }^{9,10}$ Isomerization from the most stable structure to a $\mathrm{NH} \cdots \mathrm{O}$ form has been photochemically induced in a cryogenic matrix. ${ }^{11}$ Complexation in jet-cooled conditions may also favor the less stable $\mathrm{NH} \cdots \mathrm{O}$ form, as observed in complexes between an aromatic alcohol and amino-alcohols, ${ }^{12,13}$ as well as other open forms. ${ }^{4,14}$

The paradigm for intramolecular $\mathrm{OH} \cdots \mathrm{N}$ interaction is 1,2 aminoethanol, referred to as AE hereafter. Its conformation has been the subject of numerous experimental studies in the microwave ${ }^{15,16}$ or millimeter range in the gas phase. ${ }^{17} \mathrm{IR}$ spectroscopy has been reported for AE isolated in a cryogenic matrix ${ }^{9}$ or in a supersonic expansion ${ }^{18}$ in the hydride stretch region. The vibrational spectroscopy study of gas-phase $\mathrm{AE}$ has been extended to the hydride stretch overtones region. ${ }^{19}$ The conformational preference of $\mathrm{AE}$ in polar or non-polar solvent has been studied by NMR; the gauche conformation is always favored. ${ }^{20}$ Numerous theoretical studies have been carried out in addition to the experimental approaches. ${ }^{19,21-24}$ Both gauche effects and intramolecular hydrogen bonds contribute to the increased stability of the gauche forms; while the gauche effect has been suggested to play a major role in polar solvents, intramolecular hydrogen bond is dominant in non-polar solvents or in the gas phase..$^{23,25}$ 
We revisit here the vibrational spectroscopy of AE and its dimer in the hydride stretch, mid infrared (MIR), and far infrared (FIR) regions, by means of the Jet-AILES apparatus, installed on the infrared beamline AILES at the synchrotron facility SOLEIL. ${ }^{26-28}$ This experimental setup combines a continuous supersonic expansion with a pumping capacity adapted to high molecular flows and a high resolution Fourier Transform IR (FTIR) spectrometer. It enables probing the vibrational spectroscopy of gaseous and sublimated vapors of initially liquid or solid samples controlled in flow and temperature, over the whole IR range. In the first step, such a versatile spectroscopic probe is used in conjunction with high level $a b$ initio calculations to characterize the vibrational signatures of the $\mathrm{AE}$ monomer and its structural properties. In the second step, vibrational signatures of the $\mathrm{AE}$ dimer are investigated and compared to $a b$ initio frequency calculations.

\section{EXPERIMENTAL AND THEORETICAL METHODS}

\section{A. Experimental details}

Jet-cooled spectra were recorded using the Jet-AILES apparatus, already described in detail in previous studies, and coupled to the high resolution Bruker IFS 125 FTIR spectrometer implemented on the AILES beamline at the synchrotron facility SOLEIL. ${ }^{24}$ Briefly, a slit nozzle of $60 \mathrm{~mm}$ length and $80 \mu \mathrm{m}$ width was used to expand the sample into an expansion chamber connected to a set of root pumps delivering a pumping capacity of about $1800 \mathrm{~m}^{3} \mathrm{~h}^{-1}$. Production of AE vapor from liquid AE (Aldrich, 98\% purity) was regulated using a Controlled Evaporation Mixer (Bronkhorst CEM model W303A22-K) supplied with a flow of helium or argon as a carrier gas (Bronkhorst 2-100 standard liter min $^{-1}$ (slm) model F-202AV) and liquid AE (Bronkhorst mini CORI-FLOW $1000 \mathrm{~g} \mathrm{~h}^{-1}$ model M13). To avoid sample condensation, the vapor/carrier gas line and the stagnation reservoir of the slit nozzle were both moderately heated at $310 \mathrm{~K}$.

In our supersonic expansion conditions, the backing $\mathrm{P}_{0}$ and residual $P_{1}$ pressures were typically maintained in the 150-500 Torr and 0.2-0.8 Torr ranges, respectively. Jet-cooled FT spectra of 200 co-added interferograms were recorded at $0.5 \mathrm{~cm}^{-1}$ resolution with suitable combinations of infrared sources (Globar, tungsten filament), beamsplitters (composite, $\mathrm{KBr}-\mathrm{Ge}, \mathrm{Si}-\mathrm{CaF}_{2}$ ), and detectors (InSb, HgCdTe, Sibolometer).

Static absorption experiments at room temperature were performed by injecting 0.025 Torr of vaporized $\mathrm{AE}$ gas in a multipass cell in which the optics in White-type configuration were set to obtain $150 \mathrm{~m}$ absorption path from a base length of $2.5 \mathrm{~m}$. Two polypropylene films of $50 \mu \mathrm{m}$ thickness separated the cell from the interferometer for the experiments in the far-infrared range. Globar/composite/bolometer, Globar/KBr$\mathrm{Ge} / \mathrm{HgCdTe}$, and tungsten filament $/ \mathrm{Si}-\mathrm{CaF}_{2} / \mathrm{InSb}$ configurations were used in the $100-600 \mathrm{~cm}^{-1}, 700-2000 \mathrm{~cm}^{-1}$, and $3200-3800 \mathrm{~cm}^{-1}$ spectral ranges limited by different band pass filters, respectively.

\section{B. Theoretical methods}

Both $\mathrm{AE}$ monomer and dimer structures were optimized at the second order Møller-Plesset (MP2) level, with the augmented correlation-consistent basis set aug-cc-pVTZ (AVTZ) of Dunning and co-workers. ${ }^{29,30}$ MP2 calculations were performed with the Gaussian09 package. ${ }^{31}$ Explicitly correlated coupled cluster calculations (CCSD(T)-F12) were carried out with the F12b approximation and the aug-ccpVDZ (AVDZ) basis set using the Molpro2012.1 package. ${ }^{32,33}$ Due to computational cost, CCSD(T)-F12 calculations were limited to the monomer. All geometry optimizations were performed with the "very tight" convergence criterion and stationary points were checked with harmonic frequency calculations.

For the monomer, the anharmonic frequencies were calculated at the MP2/AVTZ level of theory using the vibrational perturbation theory (VPT2) approach as implemented in Gaussian09. ${ }^{34}$ Anharmonic corrections obtained thereby were then used to correct the CCSD(T)-F12/AVDZ harmonic frequencies using Equation (1) to obtain hybrid $\operatorname{CCSD}(\mathrm{T})$ F12/MP2 anharmonic frequencies. $\omega$ and $v$ are the harmonic and anharmonic frequencies, respectively,

$$
v_{H y b r i d} C C S D(T)-F 12 / M P 2=\omega_{C C S D(T)-F 12}-\left(\omega_{M P 2}-v_{M P 2}\right) \text {. }
$$

The procedure consisting of applying anharmonicity corrections calculated at the MP2 or DFT level to the CCSD(T)F12 frequencies led to an excellent agreement between theory and experiment for floppy molecules as well as H-bonded systems. ${ }^{28,35}$

Due to computational cost, a different procedure was followed for the dimer. The harmonic frequencies of the dimer were calculated at the MP2/AVTZ level and scaled by a mode-specific scaling factor, which takes into account the anharmonicity pattern specific to each vibration mode. ${ }^{36,37}$ The mode-specific scaling factor was deduced from the ratio between the observed and calculated corresponding frequency of the monomer. It should be noted that this procedure, referred to as "hybrid $\operatorname{CCSD}(\mathrm{T})-\mathrm{F} 12 / \mathrm{MP} 2$ level," is possible only if there is a direct correlation between the mode of the dimer and a mode of the monomer.

The hydrogen bonds network was visualized with the Non-Covalent Interaction (NCI) method. ${ }^{38}$ This method and its applications to intramolecular $\mathrm{H}$-bonds have been described recently in detail. ${ }^{38-40}$ It rests on a topological analysis of the electron density $\rho$ and its reduced gradient $s(\rho)$ in regions of weak electron density and small reduced gradient. The zones where $s(\rho)$ tends to zero, i.e., zones close to the minima of electron density, are characteristic of non-covalent interactions. The visualization was accomplished by plotting iso-surfaces of the reduced gradient which codes the interactions using a RGB coloring scheme resting on the sign of the second eigenvalue, $\lambda_{2}$, of the Hessian matrix. Iso-surfaces with positive $\lambda_{2}$ are coded in red and correspond to repulsive regions, while iso-surfaces with negative $\lambda_{2}$ are coded in blue and correspond to favorable interactions. It should be noted that these red and blue iso-surfaces correspond to ring critical points (RCPs) and bond critical points (BCPs), respectively, defined in the QTAIM approach. ${ }^{41}$ In the particular case of intramolecular hydrogen bonding, the favorable hydrogen bond is always accompanied by steric constraints due to the formation of a Hbonded cycle, which appears as a bicolor blue/red iso-surface. 
Finally, regions with $\lambda_{2}$ close to zero correspond to weak delocalized interactions like dispersion and are coded in green. The color intensity and the shape of the iso-surface also give important information: the stronger the interaction, the more intense is the color and larger the reduced electron density in the isosurface. Moreover, strong directional interactions appear as small localized iso-surface, while multicentric or delocalized interactions appear as extended iso-surfaces. The input electronic density for the NCI calculations was obtained from the Gaussian .wfn output file at the MP2/AVTZ level (using Density $=$ Current keyword), and a cut-off of 0.35 was applied. The 3-D NCI images were plotted using the VMD software with an isovalue of 0.4. ${ }^{42}$

\section{EXPERIMENTAL RESULTS}

Two spectral regions were mainly investigated, namely the hydride stretch region $\left(3250-3650 \mathrm{~cm}^{-1}\right)$ and the fingerprint region $\left(850-1850 \mathrm{~cm}^{-1}\right)$, to identify the vibrational signatures of $\mathrm{AE}$ and its dimer. Figure 1 displays a series of jetcooled FT spectra recorded for different dilutions of AE/carrier gas mixtures in the hydride stretch region. An expansion of helium seeded with AE was used first to avoid cluster formation. In these conditions, only one band at $3567.8 \mathrm{~cm}^{-1}$ is observed (Figure 1(a)) with partially resolved rotational branches, assigned to the $\mathrm{AE}$ monomer. When replacing helium by argon, AE complexation is expected as evidenced in previous hydrogen bonded studies. ${ }^{28}$ At low AE concentration (Figure 1(b)), two additional features, broader than that of the monomer $\left(3567.8 \mathrm{~cm}^{-1}\right)$, appear at lower frequencies. They consist of an intense band at about $3304 \mathrm{~cm}^{-1}$ assigned to the dimer and a weaker one at $3388 \mathrm{~cm}^{-1}$. At higher $\mathrm{AE}$ concentrations a narrow band at $3430 \mathrm{~cm}^{-1}$ is clearly distinguishable, which belongs to the $\mathrm{Q}$ branch of the monomer (Figure 1(c)). Finally, the AE concentration increase from 25 to $100 \mathrm{~g} / \mathrm{h}$ is correlated with the collective growth of both broad overlapping bands around 3350 and $3388 \mathrm{~cm}^{-1}$ apparently stronger than that of the $3304 \mathrm{~cm}^{-1}$ band (Figure 1(d)). On the grounds of only AE concentration effects, no definite assignment can be proposed. The $3388 \mathrm{~cm}^{-1}$ band first observed under the same conditions as the dimer band is

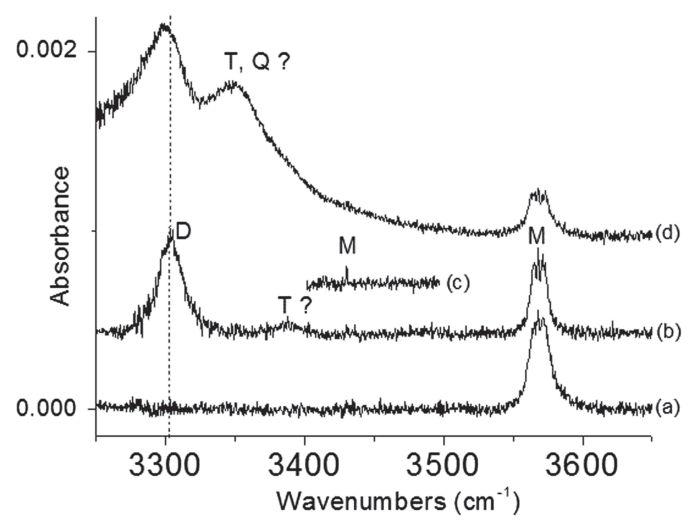

FIG. 1. Jet-AILES FTIR spectrum in the bonded $\mathrm{OH}$ stretch region of $\mathrm{AE}$ recorded at $0.5 \mathrm{~cm}^{-1}$ resolution for different dilutions of the binary mixture AE/carrier gas: (a) $50 \mathrm{~g} / \mathrm{h} \mathrm{AE}, 30 \mathrm{slm} \mathrm{He}$, (b) $25 \mathrm{~g} / \mathrm{h} \mathrm{AE}, 10 \mathrm{slm} \mathrm{Ar}$, (c) $100 \mathrm{~g} / \mathrm{h}$ AE, $10 \mathrm{slm}$ Ar, (d) $100 \mathrm{~g} / \mathrm{h} \mathrm{AE}, 20 \mathrm{slm}$ Ar. The notations M, D, T, and Q stand for monomer, dimer, trimer, and tetramer, respectively.

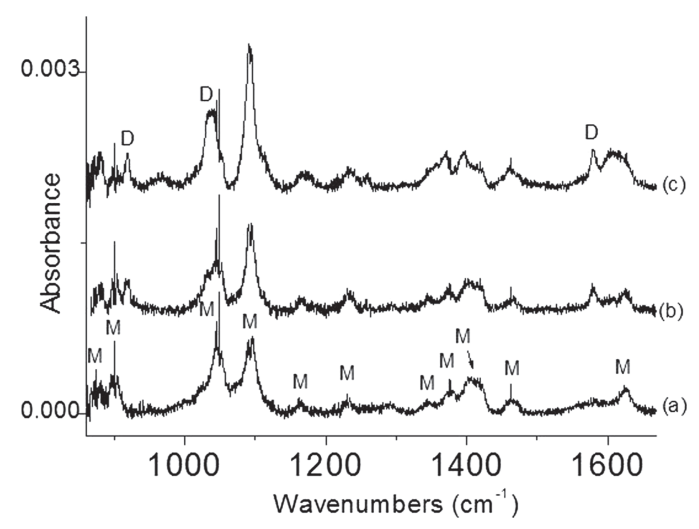

FIG. 2. Jet-AILES FTIR spectrum of AE in the fingerprint region recorded at $0.5 \mathrm{~cm}^{-1}$ resolution for different dilutions of the binary mixture $\mathrm{AE} /$ carrier gas: (a) $50 \mathrm{~g} / \mathrm{h} \mathrm{AE}, 30 \mathrm{slm} \mathrm{He}$, (b) $25 \mathrm{~g} / \mathrm{h} \mathrm{AE}, 10 \mathrm{slm} \mathrm{Ar}$, (c) $50 \mathrm{~g} / \mathrm{h} \mathrm{AE}, 20$ slm Ar. The notations $\mathrm{M}$ and $\mathrm{D}$ stand for monomer and dimer, respectively.

tentatively assigned to a trimer, while the $3350 \mathrm{~cm}^{-1}$ band could correspond to a less stable conformer of the trimer or a tetramer.

The same procedure was followed in the fingerprint region. The spectrum recorded with helium as a carrier gas (Figure 2(a)) is expected to contain only monomer bands. Twelve of them are observed, at 880, 901, 1049, 1093, 1165, $1232,1280,1343,1376,1397,1463$, and $1625 \mathrm{~cm}^{-1}$ (Table I). Few bands display an intense $\mathrm{Q}$ branch such as those at $901,1049,1376$, and $1463 \mathrm{~cm}^{-1}$. This rotational signature will give complementary information about their assignment (vide infra). Figures 2(b) and 2(c) display jet-cooled spectra

TABLE I. Frequencies observed in the gas-phase (in $\mathrm{cm}^{-1}$ ) of the $\mathrm{AE}$ monomer and dimer from this work and Ref. 9 are given. Monomer-to-dimer shifts are also given.

\begin{tabular}{lccc}
\hline \hline & Monomer & & Dimer \\
Jet & Cell & 3304 & M-D shift \\
\hline 3567.8 & $3570^{\mathrm{a}}$ & & -266 \\
3430 & $3422^{\mathrm{a}}$ & & \\
& $3356^{\mathrm{a}}$ & & \\
& $2949^{\mathrm{a}}$ & & -46 \\
& $2882^{\mathrm{a}}$ & & \\
& $2861^{\mathrm{a}}$ & & \\
1625 & $1623^{\mathrm{a}}$ & 1579 & \\
1463 & $1462^{\mathrm{a}}$ & & \\
1376 & $1385^{\mathrm{a}}$ & & \\
1343 & $1375^{\mathrm{a}}$ & & \\
1232 & $1359^{\mathrm{a}}$ & & +12 \\
1280 & $1230^{\mathrm{a}}$ & & \\
1165 & & & \\
1093 & & & \\
1049 & $1083^{\mathrm{a}}$ & & \\
901 & $1037^{\mathrm{a}}$ & & \\
880 & & & \\
774 & $858^{\mathrm{a}}$ & & \\
530 & $759^{\mathrm{a}}$ & & \\
463 & $540^{\mathrm{a}}$ & & \\
& $460^{\mathrm{a}}$ & & \\
\hline \hline
\end{tabular}

${ }^{\mathrm{a} B a n d}$ maximum in the room temperature cell-FTIR spectrum from Ref. 9.

${ }^{\mathrm{b}} \mathrm{B}$ and maximum in the room temperature cell-FTIR spectrum (this work). 


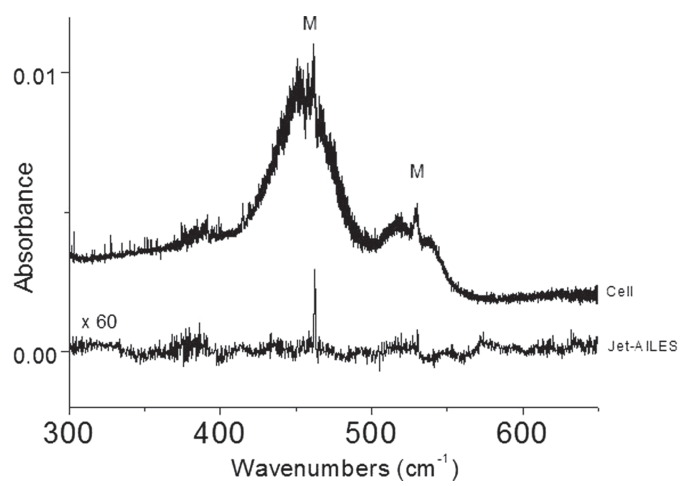

FIG. 3. FT spectra of the AE monomer recorded in the FIR range: bottom, Jet-AILES spectrum at $0.5 \mathrm{~cm}^{-1}$ resolution with $100 \mathrm{~g} / \mathrm{h} \mathrm{AE}, 30 \mathrm{slm} \mathrm{He}$; top, cell spectrum at $0.1 \mathrm{~cm}^{-1}$ resolution.

recorded with argon as a carrier gas, at different $\mathrm{AE}$ concentrations. Dimer absorption bands are expected to appear only in the spectrum recorded in argon and to increase with concentration, i.e., from Figure 2(b) (with experimental conditions identical to those of Figure 1(b)) to Figure 2(c). This is the case for the three unstructured bands observed at 919,1037, and $1579 \mathrm{~cm}^{-1}$. In the poorly sensitive $700-900 \mathrm{~cm}^{-1}$ range, jet-cooled spectra were also recorded using the same effects of dilution and nature of carrier gas to evidence monomer from dimer absorptions, but no additional dimer absorption was detected.

Finally, jet-cooled and room temperature cell spectra were both recorded in the far-infrared range $\left(100-600 \mathrm{~cm}^{-1}\right)$. A remarkable simplification of the bands observed in the cell is obtained with the Jet-AILES expansion (Figure 3). Q branches only broadened by the apparatus function of the FTIR spectrometer were observed in the jet-cooled spectrum at 463 and $530 \mathrm{~cm}^{-1}$ while the huge width of bands observed in the cell, $40-100 \mathrm{~cm}^{-1}$ full-width-at-half-maximum typically for those centered at 210,457 , and $530 \mathrm{~cm}^{-1}$, is probably due to the unresolved rotational structure of several fundamental bands, the presence of hot bands and of possible splittings related to the internal dynamics of $\mathrm{AE}$.

Finally, 17 bands were assigned to the AE monomer and 4 bands to its dimer. The observed frequencies are gathered in Table I.

In the following paragraph theoretical results will be presented, namely the set of anharmonic frequencies for the most stable $\mathrm{AE}$ monomers and the corrected harmonic frequencies for the dimer. The bands observed in the FTIR spectra will be assigned by comparing the observed frequencies and those calculated for the different isomers of AE monomer, taking into account their relative population either in the cell at room temperature or in the supersonic expansion. In addition, simulation of the band contours observed in the fingerprint region will be used to confirm the assignments to the most stable isomer and assess the contribution of the less stable ones.

\section{THEORETICAL RESULTS AND DISCUSSION}

\section{A. Monomer}

The conformation of 2-aminoethanol has been extensively studied as well as its modification upon the complexation with rare gas, water, or an aromatic alcohol. ${ }^{9,12,14,16,18,21}$ In the following, we shall refer to the notation widely used in the literature, in which the 13 possible conformers are labelled by three letters. ${ }^{9}$ The central capital letter refers to the $\mathrm{N}-\mathrm{C}-\mathrm{C}-\mathrm{O}$ dihedral angle, which amounts to $\sim+60^{\circ},-60^{\circ}, 180^{\circ}$ for $\mathrm{G}$, $\mathrm{G}^{\prime}, \mathrm{T}$, respectively. The preceding and following letters $\mathrm{g}, \mathrm{g}^{\prime}$, and $\mathrm{t}$ correspond to rotations of $\sim+60^{\circ},-60^{\circ}, 180^{\circ}$ around $\mathrm{C}-\mathrm{N}(\mathrm{C}-\mathrm{C}-\mathrm{N}-\mathrm{lp}$ dihedral angle, $\mathrm{lp}$ being the lone pair on the $\mathrm{N}$ atom) and $\mathrm{C}-\mathrm{O}(\mathrm{C}-\mathrm{C}-\mathrm{O}-\mathrm{H}$ dihedral angle), respectively. The four most stable isomers of AE are shown in Figure 4. Cartesian coordinates of each structure are reported in Part 1 of the supplementary material. The most stable conformation is $\mathrm{g}^{\prime} \mathrm{Gg}^{\prime}$, as it was concluded in all previous theoretical and experimental studies. It shows an intramolecular $\mathrm{OH} \cdots \mathrm{N}$ hydrogen bond that clearly appears as a bicolor analysis in the 3D NCI plot, as already reported. ${ }^{19}$ The signature of the hydrogen bond appears as the blue component of the pellet while that of the ring closure corresponds to the red part. The other conformers are calculated at higher energy and display a weaker intramolecular hydrogen bond, either $\mathrm{OH} \cdots \mathrm{N}$ $\left(\mathrm{gGg}^{\prime}\right)$ or $\mathrm{NH} \cdots \mathrm{O}$ (gGt and $\left.\mathrm{tGt}\right)$. In the three higher-energy conformers, the weaker H-bonding interaction is accompanied by a lesser ring closure constrain, as evidenced by the lighter blue and red colors seen in the NCI plots. The stronger intramolecular interaction in $\mathrm{g}^{\prime} \mathrm{Gg}^{\prime}$ also manifests itself by a larger electronic density at the critical point characteristic of the hydrogen bond ( 0.0205 for $\mathrm{g}^{\prime} \mathrm{Gg}^{\prime}$ vs. 0.0119 for $\mathrm{gGt}$, 0.0127 for $\mathrm{gGg}^{\prime}$ and 0.0113 for $\mathrm{tGt}$ ). It should be noted also that the critical density is larger for the conformers showing an $\mathrm{OH} \cdots \mathrm{N}$ bond $\left(\mathrm{g}^{\prime} \mathrm{Gg}^{\prime}\right.$ and $\left.\mathrm{gGt}\right)$ than those with a weaker $\mathrm{NH} \cdots \mathrm{O}$ interaction.

The ground state rotational constants computed at the MP2/AVTZ level for the four isomers shown in Figure 4 are reported in Table II as well as the planar moment
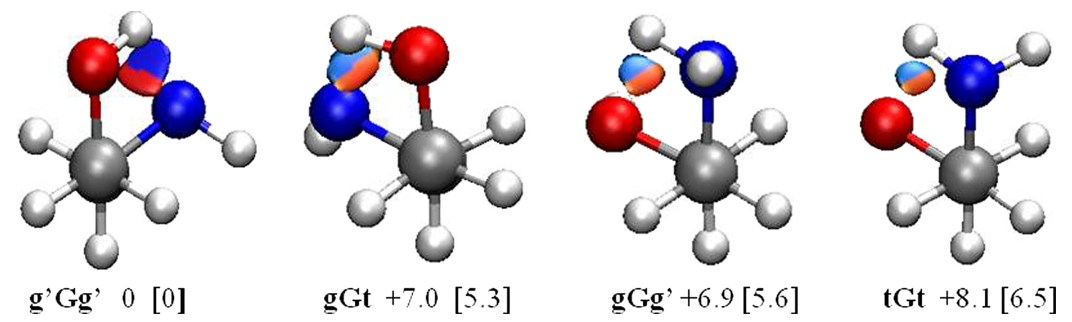

FIG. 4. 3D NCI plot of the four most stable isomers of $\mathrm{AE}$ monomer. The group in front is that acting as a hydrogen-bond donor, namely $\mathrm{OH}$ for $\mathrm{g}^{\prime} \mathrm{Gg}^{\prime}$ and $\mathrm{gGg}^{\prime}$ and $\mathrm{NH}$ for gGt and tGt. Electronic and [ZPE corrected] relative energy $(\mathrm{kJ} / \mathrm{mol})$ at the CCSD(T)-F12/AVDZ level of theory are also reported. Note the bicolored isosurface characteristic of intramolecular interaction and the more intense color in $\mathrm{g}^{\prime} \mathrm{Gg}^{\prime}$, which shows a stronger interaction. 
TABLE II. Calculated hybrid CCSD(T)-F12/MP2 anharmonic frequencies $\left(\mathrm{cm}^{-1}\right)$ for the four most stable isomers of AE and MP2/AVTZ IR intensities at the harmonic level $(\mathrm{km} / \mathrm{mol})$ are given in parentheses. IR intensities (\%) relative to that of $v_{\mathrm{OHb}}$ are reported in square brackets for $\mathrm{g}^{\prime} \mathrm{Gg}^{\prime}$ for easier comparison between experiment and calculations. IP: in phase vibrations. OOP: out of phase vibrations. Equilibrium rotational constants (denoted by subscript e) at the $\operatorname{CCSD}(\mathrm{T})$-F12 and MP2 level (in parentheses). Ground state rotational constants (denoted by subscript 0 ) at the MP2 level (in parentheses). $\Delta P_{\mathrm{cc}}\left(\mathrm{u} \AA^{2}\right)$ is the difference between experimental and calculated planar moment of inertia $\mathrm{P}_{\mathrm{cc}}$.

\begin{tabular}{|c|c|c|c|c|c|}
\hline \multirow[b]{2}{*}{ Isomer: } & \multirow[b]{2}{*}{ Expt. } & \multicolumn{4}{|c|}{ Ab initio } \\
\hline & & $\mathrm{g}^{\prime} \mathrm{Gg}^{\prime}$ & $\mathrm{gGt}$ & $\mathrm{gGg}^{\prime}$ & tGt \\
\hline \multicolumn{6}{|l|}{ Mode } \\
\hline$v_{\mathrm{OHb}}$ & 3567.8 [100] & 3575 (74) [100] & $3692(45)$ & 3631 (37) & $3692(45)$ \\
\hline$v_{\mathrm{NH}_{2}}$ asym & $3430[10]$ & 3432 (9) [13] & $3421(10)$ & $3441(10)$ & $3411(8)$ \\
\hline$v_{\mathrm{NH}_{2} \mathrm{sym}}$ & & 3357 (1) [2] & $3352(2)$ & 3375 (1) & $3344(2)$ \\
\hline$v_{\mathrm{CH}}$ asym IP & & 2959 (28) [38] & $2936(27)$ & $2956(30)$ & $2951(22)$ \\
\hline$v_{\mathrm{CH} \text { asym OOP }}$ & & $2950(21)[29]$ & $2922(36)$ & $2942(27)$ & $2921(64)$ \\
\hline$v_{\mathrm{CH} \text { sym IP }}$ & & $2844(55)[75]$ & $2859(46)$ & $2927(38)$ & $2911(5)$ \\
\hline$v_{\mathrm{CH} \text { sym OOP }}$ & & $2835(52)[70]$ & $2834(45)$ & $2911(38)$ & $2856(51)$ \\
\hline$\delta_{\mathrm{NH}_{2}}$ & $1625[70]$ & $1622(29)$ [39] & $1570(33)$ & 1615 (27) & $1583(22)$ \\
\hline$\delta_{\mathrm{CH}_{2}}$ & & 1469 (1) [2] & $1466(4)$ & $1460(1)$ & $1469(5)$ \\
\hline$\delta_{\mathrm{CH}_{2}}$ & $1463[30]$ & 1457 (5) [7] & $1455(5)$ & $1440(5)$ & $1442(3)$ \\
\hline$\omega_{\mathrm{CH}_{2}}$ & 1397 [100] & $1403(47)[64]$ & $1419(3)$ & $1384(20)$ & $1408(1)$ \\
\hline$\omega_{\mathrm{CH}_{2}}$ & $1376[40]$ & $1373(13)[18]$ & $1376(6)$ & $1368(15)$ & $1361(1)$ \\
\hline$\delta_{\mathrm{COH}}$ & 1343 [20] & 1341 (7) [9] & $1304(7)$ & $1357(6)$ & $1349(9)$ \\
\hline$\tau_{\mathrm{NH}_{2}}$ & $1280[10]$ & $1293(3)$ [4] & $1250(33)$ & $1314(4)$ & $1271(23)$ \\
\hline$\tau_{\mathrm{CH}_{2}}$ & $1232[40]$ & $1236(24)[32]$ & $1220(3)$ & $1199(11)$ & 1224 (17) \\
\hline$\tau_{\mathrm{CH}_{2}}$ & $1165[20]$ & $1166(7)[9]$ & $1147(0)$ & $1169(1)$ & $1136(2)$ \\
\hline$v_{\mathrm{CN}, \mathrm{CO} s y \mathrm{~m}}$ & 1093 [210] & 1098 (44) [59] & $1090(36)$ & $1097(35)$ & $1102(10)$ \\
\hline$v_{\mathrm{CN}, \mathrm{CO} \text { asym }}$ & 1049 [240] & $1045(52)[70]$ & 1077 (18) & $1034(15)$ & $1074(71)$ \\
\hline$\tau_{\mathrm{NH}_{2}}$ & & 986 (7) [9] & $1024(56)$ & $1028(72)$ & $1001(23)$ \\
\hline$\omega_{\mathrm{NH}_{2}}$ & 901 [40] & 901 (46) [62] & $885(5)$ & $866(14)$ & $882(62)$ \\
\hline$v_{\mathrm{CC}}$ & $880[30]$ & 869 (14) [19] & $853(54)$ & 806 (104) & $842(85)$ \\
\hline$\omega_{\mathrm{NH}_{2}}$ & 774 [180] & $787(85)[115]$ & $820(85)$ & $819(5)$ & $815(38)$ \\
\hline$\tau_{\mathrm{OH}}$ & 530 [70] & 497 (90) [121] & $495(15)$ & $517(13)$ & $505(17)$ \\
\hline$\tau_{\mathrm{OH}}$ & $463[20]$ & 495 (32) [43] & $345(4)$ & $389(100)$ & $339(25)$ \\
\hline$\delta_{\mathrm{OCCN}}$ & & 318 (1) [1] & $246(45)$ & $320(1)$ & $254(27)$ \\
\hline$\tau_{\mathrm{NH}_{2}}$ & 210 & 237 (11) [15] & 188 (109) & $121(11)$ & $228(88)$ \\
\hline$\tau_{\mathrm{OCCN}}$ & & $175(6)[8]$ & $168(10)$ & $<102^{\mathrm{a}}(72)$ & $164(23)$ \\
\hline $\mathrm{A}_{\mathrm{e}}$ & & $0.4843(0.4831)$ & $0.5036(0.5026)$ & $0.4825(0.4829)$ & $0.4989(0.4989)$ \\
\hline $\mathrm{A}_{0}$ & $0.4840^{\mathrm{b}}$ & $(0.4699)$ & $(0.4958)$ & $(0.4781)$ & $(0.4948)$ \\
\hline $\mathrm{B}_{\mathrm{e}}$ & & $0.1878(0.1888)$ & $0.1824(0.1831)$ & $0.1877(0.1877)$ & $0.1787(0.1790)$ \\
\hline $\mathrm{B}_{0}$ & $0.1850^{\mathrm{b}}$ & $(0.1859)$ & $(0.1805)$ & $(0.1845)$ & $(0.1768)$ \\
\hline $\mathrm{C}_{\mathrm{e}}$ & & $0.1544(0.1549)$ & $0.1517(0.1521)$ & $0.1509(0.1510)$ & $0.1499(0.1500)$ \\
\hline $\mathrm{C}_{0}$ & $0.1525^{\mathrm{b}}$ & $(0.1533)$ & $(0.1501)$ & $(0.1490)$ & $(0.1482)$ \\
\hline $\mathrm{P}_{\mathrm{cc}}$ & $-166.9^{\mathrm{b}}$ & -164.9 & -171.7 & -169.2 & -175.1 \\
\hline$\Delta \mathrm{P}_{\mathrm{cc}}$ & $\cdots$ & -2.0 & 4.8 & 2.3 & 8.2 \\
\hline
\end{tabular}

${ }^{\mathrm{a}}$ Harmonic value. A failure of VPT2 on this mode leads to negative anharmonic frequency.

${ }^{\mathrm{b}}$ Reference 16 .

of inertia $\mathrm{P}_{\mathrm{cc}}$ and its difference $\Delta \mathrm{P}_{\mathrm{cc}}$ with the experimental value. The ground state rotational constants are very similar to each other. In particular, both $\mathrm{g}^{\prime} \mathrm{Gg}^{\prime}$ and $\mathrm{gGg}^{\prime}$ isomers could match the experimental constants obtained by Tubergen et al. ${ }^{16}$ On the basis of energetic criteria and $\Delta \mathrm{P}_{\mathrm{cc}}$, the observed isomer can be safely assigned to $\mathrm{g}^{\prime} \mathrm{Gg}^{\prime}$, in agreement with Tubergen's conclusions. Very good agreement between our calculations and the experiment was found for $\mathrm{B}_{0}$ and $\mathrm{C}_{0}$ within $0.5 \%$. On the other hand, the agreement is not satisfactory for $\mathrm{A}_{0}$ which shows an error of $3 \%$ relative to the experimental value. As the $\mathrm{A}_{\mathrm{e}}$ values calculated at the MP2 or $\operatorname{CCSD}(\mathrm{T})-\mathrm{F} 12$ levels are nearly identical $\left(0.4831 \mathrm{~cm}^{-1}\right.$ and $0.4843 \mathrm{~cm}^{-1}$, respectively), the difference between MP2 and experimental $\mathrm{A}_{0}$ values is not due to a problem of electronic correlation treatment but rather to an overestimation of the anharmonic correction.

The hybrid CCSD(T)-F12/MP2 anharmonic frequencies of the four most stable isomers of AE are reported in Table II as well as the corresponding experimental data. Harmonic and anharmonic MP2/AVTZ frequencies are reported in Part 2 of the supplementary material, as well as harmonic $\operatorname{CCSD}(\mathrm{T})$ F12/AVDZ frequencies.

The IR vibrational signatures computed for the four $\mathrm{AE}$ isomers clearly differ from each other. Comparison of the computed anharmonic frequencies and those attributed to the AE monomer in the experimental spectrum leads to the unambiguous conclusion that the observed isomer is $\mathrm{g}^{\prime} \mathrm{Gg}^{\prime}$. The agreement between the theory and experiment is 
excellent for the frequencies between 3600 and $900 \mathrm{~cm}^{-1}$ (with a root-means-square deviation (RMSD) of $4 \mathrm{~cm}^{-1}$ and a maximum deviation of $7 \mathrm{~cm}^{-1}$ ). It is however less satisfactory for the frequencies below $900 \mathrm{~cm}^{-1}$, with an RMSD of $25 \mathrm{~cm}^{-1}$ and a maximum deviation of $33 \mathrm{~cm}^{-1}$. This reflects the limits of the VPT2 approach and its difficulties in describing large amplitude low frequency vibrational modes. ${ }^{43}$

We searched for other contributions than the fundamental bands of the $\mathrm{g}^{\prime} \mathrm{Gg}^{\prime}$ isomer of the AE monomer in the FTIR spectra. An additional proof of the spectral assignments can be provided by band contour simulations of the most intense fundamental bands of the four most stable isomers of AE. The simulation has been performed in the $800-1850 \mathrm{~cm}^{-1}$ fingerprint region using the computed ground and excited state rotational parameters, band centers, and intensities. The intensity cutoff for $\mathrm{g}^{\prime} \mathrm{Gg}^{\prime}$ is $7 \mathrm{~km} / \mathrm{mol}$, which represents our detection threshold in jet. A relatively low cutoff $(30 \mathrm{~km} / \mathrm{mol})$ is fixed for the less stable ones to account for the error bar in the calculated intensities. The band type has been determined from the projection of the dipole moment derivatives on the principal inertia axes using the $\operatorname{IOP}(7 / 33=1)$ keyword in Gaussian09 for MP2/AVTZ harmonic frequencies calculation.

In the first step, vibrational signatures of the three less stable isomers in jet-cooled conditions should be assessed. Especially in the $800-1100 \mathrm{~cm}^{-1}$ range, the cumulative intensities of $\omega_{\mathrm{NH}_{2}}, v_{\mathrm{CC}}$, and the in-phase or out-of-phase combinations of the $\mathrm{CN}$ and $\mathrm{CO}$ stretches (noted $v_{\mathrm{CN}, \mathrm{CO}}$ sym and

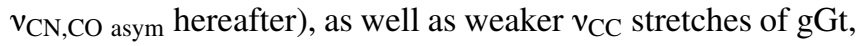
$\mathrm{gGg}^{\prime}$, and $\mathrm{tGt}$, could lead to a residual spectral background which would result to an overestimated experimental intensities of both symmetric and asymmetric $v_{\mathrm{CN}, \mathrm{CO}}$ stretching bands at 1049 and $1093 \mathrm{~cm}^{-1}$ (Table II). The progressive disappearance of such a background in both spectra of Figures 2(b) and 2(c) correlates well with a more efficient relaxation towards the most stable isomer $\mathrm{g}^{\prime} \mathrm{Gg}^{\prime}$ in argon seeded expansions.

A delicate point is to properly estimate the relative population of the isomers $\mathrm{g}^{\prime} \mathrm{Gg}^{\prime} / \mathrm{gGt} / \mathrm{gGg}^{\prime} / \mathrm{tGt}$ (predicted to be $76 / 8 / 8 / 8$ at room temperature from a Boltzmann distribution calculation). From the jet-cooled FTIR spectra it is out of reach to derive the vibrational temperature in absence of hot bands and thereby to calculate the Boltzmann distribution. However, we could extract an upper limit for this relative population of the isomers by considering the $v_{\mathrm{OHb}}$ mode, experimentally observed for the $\mathrm{g}^{\prime} \mathrm{Gg}^{\prime}$ isomer (Figure 1) with a signal-to-noise ratio of about 20 . In $\mathrm{gGt}, \mathrm{gGg}^{\prime}$, and $\mathrm{tGt}$, the corresponding mode is expected to be $50-120 \mathrm{~cm}^{-1}$ higher in energy than in $\mathrm{g}^{\prime} \mathrm{Gg}^{\prime}$, but is not observed (Table II). Taking into account the intensities calculated for the four isomers (Table II), the upper limit of the relative population could be estimated to $82 / 6 / 6 / 6$, which represents the most favorable case to observe less stable isomers in the jet-cooled spectra. Introducing this ratio in our band contour simulations proves that the contribution of less stable isomers is almost negligible in the fingerprint region (Figure 5(c)), even in the $800-1100 \mathrm{~cm}^{-1}$ range where the contribution of less stable isomers only cannot explain the large differences observed between the experimental and theoretical intensities of both $v_{\mathrm{CN}, \mathrm{CO} \text { sym }}$ and $v_{\mathrm{CN}, \mathrm{CO} \text { asym }}$ bands.

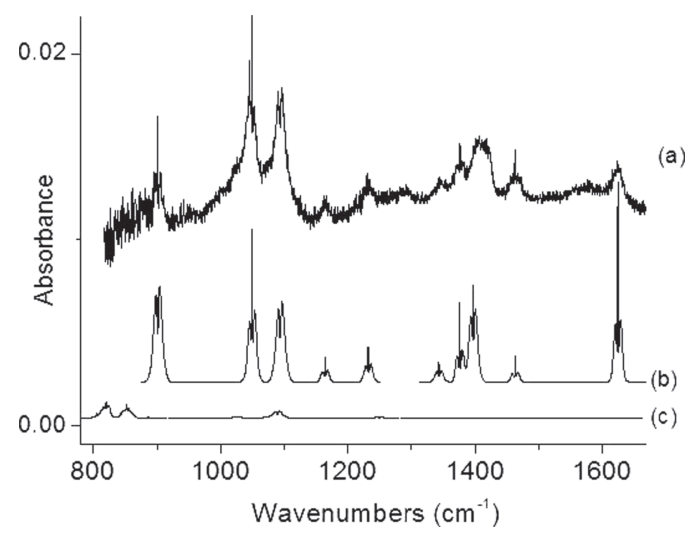

FIG. 5. Comparison between the He seeded jet-cooled FTIR spectrum of AE $50 \mathrm{~g} / \mathrm{h} \mathrm{AE}, 30 \mathrm{slm} \mathrm{He}, 0.5 \mathrm{~cm}^{-1}$ resolution (a) and simulated band contours of $\mathrm{AE}$ for the $\mathrm{g}^{\prime} \mathrm{Gg}^{\prime}$ isomer (b) for $\mathrm{gGt}, \mathrm{gGg}^{\prime}$, and $\mathrm{tGt}$ isomers (c).

On the other hand, the cumulative intensities of the bands due to less stable isomers in the FIR range $\left(180-400 \mathrm{~cm}^{-1}\right)$ are of the same order as that due to the $\mathrm{g}^{\prime} \mathrm{Gg}^{\prime}$ isomer (Table II). Low frequency motions such as $\tau_{\mathrm{NH}_{2}}$, and in lesser extent $\delta_{\mathrm{OCCN}}$ bands of gGt and tGt, should notably contribute to the $100 \mathrm{~cm}^{-1}$ fwhm band centered at $210 \mathrm{~cm}^{-1}$. On the other hand, the $\tau_{\mathrm{OH}}$ band of $\mathrm{gGg}^{\prime}$ calculated at $389 \mathrm{~cm}^{-1}$ agrees well with the small shoulder unassigned until now and observed at $\sim 380 \mathrm{~cm}^{-1}$ in the cell spectrum (Figure 3).

Band contour simulations of the main fundamentals of the most stable $\mathrm{g}^{\prime} \mathrm{Gg}^{\prime}$ isomer are shown in Figure 5(b) for the fingerprint region and compared to the jet-cooled FTIR spectrum recorded in helium (Figure 5(a)). A relatively good agreement is observed between experimental and calculated band contours, except for the $v_{\mathrm{CC}}$ and $\delta_{\mathrm{NH}_{2}}$ bands at 901 and $1625 \mathrm{~cm}^{-1}$ for which the band contour differences observed could indicate the presence of vibrational coupling with low-frequency large amplitude motions.

Finally, the most intense combination or overtone bands of the $\mathrm{g}^{\prime} \mathrm{Gg}^{\prime}$ isomer have been examined to check if they could contribute to the jet-cooled FTIR spectra. Although VPT2 undergoes some limitations for overtone bands, ${ }^{44}$ a satisfactory agreement is obtained between our calculations and the $2 v_{\mathrm{OHb}}$ and $2 v_{\mathrm{NH}_{2} \text { asym }}$ or $2 v_{\mathrm{NH}_{2} \text { sym }}$ modes observed by Thomsen et al. at $6944 \mathrm{~cm}^{-1}$ and $6613 \mathrm{~cm}^{-1} .{ }^{19}$ The corresponding frequencies calculated here are 6957 for $2 v_{\mathrm{OHb}}$ and 6717 and $6639 \mathrm{~cm}^{-1}$ for $2 v_{\mathrm{NH}_{2}}$ asym or $2 v_{\mathrm{NH}_{2} \text { sym }}$, respectively, which gives confidence in the proposed assignments. Three combination bands are therefore likely to appear in the fingerprint region: the $\left(\tau_{\mathrm{NH}_{2}}+\tau_{\mathrm{OCCN}}\right)$ mode at $1047 \mathrm{~cm}^{-1}$ (intensity $\approx 20 \mathrm{~km} / \mathrm{mol}$ ) contributes to the background below the $v_{\mathrm{CN}, \mathrm{CO} \text { asym }}$ band, and both $\left(\tau_{\mathrm{CH}_{2}}+\tau_{\mathrm{NH}_{2}}\right)$ and $\left(v_{\mathrm{CN}, \mathrm{CO} \text { asym }}\right.$ $+\delta_{\text {OCCN }}$ ) modes located at 1403 and $1416 \mathrm{~cm}^{-1}$ with intensities of 14 and $10 \mathrm{~km} / \mathrm{mol}$, respectively, could be involved in the shoulder on the high-energy side of the $\omega_{\mathrm{CH}_{2}}$ mode at $1397 \mathrm{~cm}^{-1}$.

\section{B. Dimer}

Due to the competition between inter- and intra-molecular hydrogen bonding, several dimer geometries should be taken into account. The anticipated structures, depicted in Figure 6, 
<smiles>CCCCOC1NCCOCN1</smiles>

Insertion<smiles>OCCN[C@H]1CNCCO1</smiles>

Addition

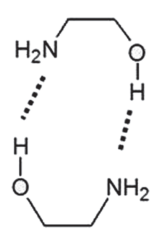

Head-to-Head
FIG. 6. Schematic anticipated structures for the AE dimer.

are as follows: first, the insertion structure is obtained by inserting the $\mathrm{OH}$ group of a sub-unit into the hydrogen bond of the other. An $\mathrm{OH} \cdots \mathrm{OH} \cdots \mathrm{NH}_{2}$ motif is formed. Although the intramolecular $\mathrm{OH} \cdots \mathrm{N}$ bond of the acceptor is not disrupted, it is slightly distorted so that the $\mathrm{OH}$ group of the donor can be inserted. As a result, the $\mathrm{OH}$ of the donor acts as a double donor, towards the two $\mathrm{NH}_{2}$ groups, as well as an acceptor from the $\mathrm{OH}$ of the other molecule in the addition structure, monomers are bounded by only one $\mathrm{OH} \cdots \mathrm{N}$ intermolecular bond. In the head-to-head structure, the two intramolecular hydrogen bonds open up. The monomers are bounded by two $\mathrm{OH} \cdots \mathrm{N}$ intermolecular bonds, forming a cyclic dimer as in the case of carboxylic acid. ${ }^{45}$ Except from the acceptor unit of the insertion structure, dimers are composed of the less stable gGt monomeric form. Although kinetics of dimerization is hard to assess, the $\mathrm{OH} \cdots \mathrm{N}$ intramolecular hydrogen bond of the $\mathrm{g}^{\prime} \mathrm{Gg}^{\prime}$ form seems to open up to the benefit of strong $\mathrm{OH} \cdots \mathrm{N}$ intermolecular interactions so that the monomers adopt a structure optimizing intramolecular $\mathrm{NH} \cdots \mathrm{O}$ interactions. It should also be noted that, like ethylene glycol, AE has transient chirality and may be cooled down in its P or M enantiomer. ${ }^{46}$ Dimers of identical or opposite chirality have therefore been taken into account in the conformational search and optimization procedure.

The energetics of selected dimers is presented in Table III as well as relevant molecular parameters. The optimized Cartesian coordinates of each structure are reported in Part 3 of the supplementary material. The 3-D NCI plots as well as densities at the relevant critical points are reported in Part 4 of the supplementary material. The dimers listed in Table III are not exhaustive and must be seen as illustrative examplesof the possible structures (Fig. 7). The monomer geometry

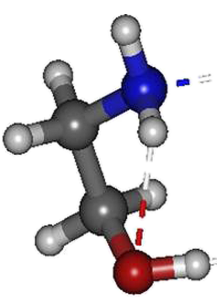

a)
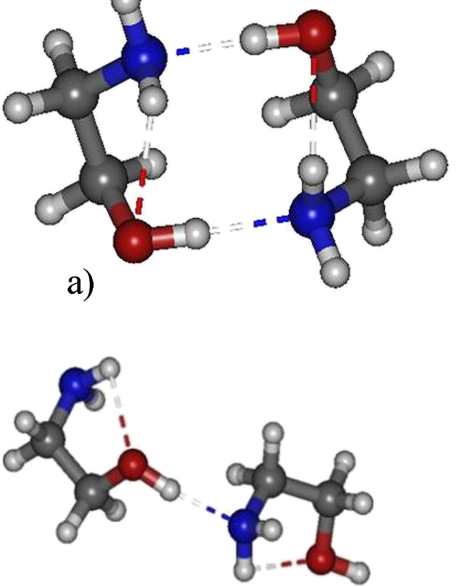

c)

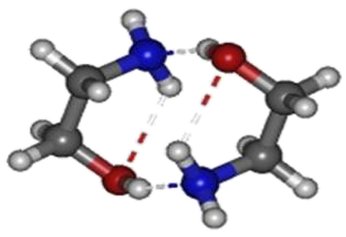

b)

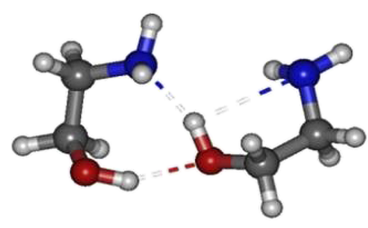

d)
FIG. 7. MP2/AVTZ calculated structures listed in Table III. (a) Homochiral head-to-head (b) heterochiral head-to-head (c) addition structure (d) insertion structure.

is strongly distorted in all the calculated structures. Insertion and addition dimers can be safely discarded as they lie much higher in energy than head-to-head dimers. Moreover, the nonequivalence of the $\mathrm{OH}$ groups in addition dimers results in distinct $\mathrm{OH}$ stretch bands of comparable intensity, which does not correspond to the observed spectrum (see hereafter).

The head-to-head dimer can be formed either in a homochiral or heterochiral manner. The homochiral dimer is by far the most stable one. Chirality synchronization has been already observed in systems showing transient chirality, either homochiral preference as in the ethylene glycol dimer or preference for monomers of opposite chirality like in the 2fluoroethanol dimer. ${ }^{47,48}$ In the case described here, the energy difference amounts to $9.8 \mathrm{~kJ} / \mathrm{mol}$. The structural differences between heterochiral and homochiral dimers are related to the balance between intermolecular and intramolecular hydrogen bonds. The heterochiral dimer shows longer intermolecular $\mathrm{OH} \cdots \mathrm{N}$ hydrogen bonds, not completely counterbalanced by stronger intramolecular NH. . O bonds. From energetic considerations, the observed dimer can be safely assigned to the homochiral head-to-head dimer. This assignment is confirmed by the analysis of the IR spectrum, performed using the

TABLE III. Energetics of selected stable structures of the dimer at the MP2/AVTZ level of theory. For dissymmetric dimers, M1 (M2) stands for the molecule located on the left (right) hand side in Figure 6.

\begin{tabular}{|c|c|c|c|c|c|c|}
\hline Molecule & $\Delta \mathrm{E}^{\mathrm{a}}(\mathrm{kJ} / \mathrm{mol})$ & Structure & $\mathrm{OH} \cdots \mathrm{N}$ (intra) $(\AA)$ & $\mathrm{NH} \cdots \mathrm{O}$ (intra) $(\AA)$ & $\mathrm{OH} \cdots \mathrm{N}$ (inter) $(\AA)$ & $\mathrm{O}-\mathrm{C}-\mathrm{C}-\mathrm{N}$ angle (deg) \\
\hline Monomer & $\ldots$ & $\mathrm{g}^{\prime} \mathrm{Gg}^{\prime}$ & 2.23 & $\ldots$ & $\ldots$ & 57 \\
\hline \multirow[t]{2}{*}{ Head-to-head homochiral } & \multirow[t]{2}{*}{0} & \multirow[t]{2}{*}{ Distorted $\mathrm{gGg}^{\prime}$} & \multirow[t]{2}{*}{$\ldots$} & M1: 2.51 & M1: 1.89 & M1: 55 \\
\hline & & & & M2: 2.51 & M2: 1.89 & M2: 55 \\
\hline \multirow[t]{2}{*}{ Head-to-head heterochiral } & \multirow[t]{2}{*}{+9.8} & M1: $\mathrm{gG}^{\prime} \mathrm{g}^{\prime}$ & \multirow[t]{2}{*}{$\ldots$} & M1: 2.29 & M1: 1.89 & M1: -49 \\
\hline & & M2: $g^{\prime} \mathrm{Gg}$ & & M2: 2.29 & M2: 1.89 & M2: 49 \\
\hline \multirow[t]{2}{*}{$\mathrm{N}$-addition } & \multirow[t]{2}{*}{+26.7} & M1: tGt (donor) & $\ldots$ & M1: 2.49 & \multirow{2}{*}{ M1: 1.87} & M1: 60 \\
\hline & & M2: tGg (acceptor) & & M2: 2.46 & & M2: 60 \\
\hline \multirow[t]{2}{*}{ Insertion } & \multirow[t]{2}{*}{+14.5} & M1: Distorted $\mathrm{g}^{\prime} \mathrm{Gg}^{\prime}$ & M1: 2.76 & & $\mathrm{OH}(\mathrm{M} 2) \cdots \mathrm{N}(\mathrm{M} 1): 1.96$ & \\
\hline & & $\begin{array}{l}\text { M2: Distorted } \mathrm{gGg}^{\prime} \\
\text { (inserted) }\end{array}$ & M2: 2.65 & $\ldots$ & $\mathrm{OH}(\mathrm{M} 1) \cdots \mathrm{O}(\mathrm{M} 2): 1.84$ & M2: 63 \\
\hline
\end{tabular}

${ }^{\mathrm{a}}$ Harmonic ZPE-corrected. 
TABLE IV. Harmonic frequencies $\omega$ of the most intense MP2/AVTZ vibrational modes, experimental frequencies $v$ for the AE dimer and monomer, scaling factor $v / \omega$, and scaled frequencies for the dimer (see text). IR intensities for the dimer are given in parentheses (km/mol). Frequency shifts from corresponding monomer frequencies are reported in squared brackets. All wavenumbers are in $\mathrm{cm}^{-1}$. IP: in phase vibrations. OOP: out of phase vibrations.

\begin{tabular}{|c|c|c|c|c|c|c|c|}
\hline \multicolumn{4}{|c|}{ AE monomer $\left(\mathrm{g}^{\prime} \mathrm{Gg}^{\prime}\right)$} & \multicolumn{4}{|c|}{ AE Dimer (head to head homochiral) } \\
\hline \multirow[b]{2}{*}{ Mode } & \multirow{2}{*}{$\begin{array}{c}\text { Expt. } \\
v\end{array}$} & \multicolumn{2}{|c|}{ Ab initio } & \multirow[b]{2}{*}{ Mode } & \multicolumn{2}{|c|}{ Ab initio } & \multirow{2}{*}{$\begin{array}{c}\text { Expt. } \\
v\end{array}$} \\
\hline & & $\omega$ & $v / \omega$ & & $\omega$ (IR int) & Scaled & \\
\hline \multirow[t]{2}{*}{$v_{\mathrm{OH}}$} & \multirow[t]{2}{*}{3567.8} & \multirow[t]{2}{*}{3733} & \multirow[t]{2}{*}{0.956} & OOP & $3412(1728)$ & $3261[-307]$ & $3304[-264]$ \\
\hline & & & & IP & $3383(74)$ & $3234[-334]$ & $\ldots$ \\
\hline \multirow{2}{*}{$\begin{array}{l}\delta_{\mathrm{NH}_{2}} \\
\ldots\end{array}$} & \multirow[t]{2}{*}{1625} & \multirow{2}{*}{$\begin{array}{c}1651 \\
\ldots\end{array}$} & 0.984 & \multirow[t]{2}{*}{ IP } & $1630(63)$ & $1605[-20]$ & $1579[-46]$ \\
\hline & & & $\ldots$ & & $1139(44)$ & . & $\ldots$ \\
\hline \multirow[t]{2}{*}{$v_{\mathrm{CN}}, \mathrm{CO}$ sym } & \multirow[t]{2}{*}{1093} & \multirow[t]{2}{*}{1125} & \multirow[t]{2}{*}{0.972} & IP & $1135(46)$ & $1103[+10]$ & $\ldots$ \\
\hline & & & & OOP & $1124(59)$ & $1093[0]$ & $\ldots$ \\
\hline \multirow[t]{2}{*}{$v_{\mathrm{CN}, \mathrm{CO} \text { asym }}$} & 1049 & 1075 & 0.976 & OOP & $1057(58)$ & $1032[-17]$ & $1037[-12]$ \\
\hline & 901 & 934 & 0.965 & OOP & $954(199)$ & $921[+19]$ & $919[+18]$ \\
\hline$\tau_{\mathrm{OH}}$ & 530 & 555 & 0.955 & OOP & 805 (68) & $769[+239]$ & $\ldots$ \\
\hline
\end{tabular}

MP2/AVTZ harmonic frequencies scaled by the modespecific scaling factor. The assignment has been done taking into account the most intense modes $(>40 \mathrm{~km} / \mathrm{mol})$ of the most stable conformer (head to head homochiral dimer) in the spectral windows covered by the experiment. Table IV gathers the selected computed frequencies for the head-to-head homochiral dimer and the $\mathrm{g}^{\prime} \mathrm{Gg}^{\prime}$ monomer, as well as the corresponding experimental frequencies and the mode-specific scaling factors. Experimental and theoretical frequency shifts from monomer to dimer are also reported.

The analysis of Table IV leads to the following observations. First, the scaling factor for the modes involving the $\mathrm{OH}$ group $(v(\mathrm{OH})$ and $\tau(\mathrm{OH}))$ is very close to the 0.958 value proposed as an "average" scaling factor for the MP2/AVTZ method. ${ }^{37}$ Second, the agreement between calculated and experimental frequencies depends on the mode: both scaled frequencies and shifts are in excellent agreement with experiment, for the mode observed at 919 and $1037 \mathrm{~cm}^{-1}$. The agreement is not as good but still satisfactory for the deformation mode involving the $\mathrm{NH}_{2}$ group $\delta_{\mathrm{NH}_{2}}$. The discrepancy arises from the fact that the scaling factor calculated from the monomer does not take into account the anharmonicity arising from the coupling with intermolecular vibrational modes. This effect often is important in hydrogen-bonded systems, especially when water is involved. ${ }^{43,49-51}$ The red shift of $v_{\mathrm{OH}}$ is overestimated in our calculation, most probably due to both the well-known overestimation of the hydrogen bond strength by MP2, the modification of both diagonal and non-diagonal anharmonicity upon dimerization, and the uncalculated coupling with intermolecular modes. ${ }^{52,53}$ Moreover, the strong IR intensity $(1728 \mathrm{~km} / \mathrm{mol})$ calculated for the out of phase $v_{\mathrm{OH}}$ mode is consistent with the strong band observed at $3304 \mathrm{~cm}^{-1}$. The $v_{\mathrm{CN}, \mathrm{CO} \text { sym }}$ band observed at $1093 \mathrm{~cm}^{-1}$ for the $\mathrm{AE}$ monomer is computed nearly unchanged in the dimer and might be hidden by that of the monomer. However the small shoulder present around $1105 \mathrm{~cm}^{-1}$ (see Figure 2(c)) could correspond to the in phase $v_{\mathrm{CN}, \mathrm{CO} \text { sym }}$ but also to the delocalized mode with a harmonic frequency of $1139 \mathrm{~cm}^{-1}$. For this mode, there is no direct correspondence between a monomer and the dimer mode, due to the deformation of the monomer upon dimerization. The use of the scaling procedure was therefore not possible. Both modes are weak and the shoulder probably is a superposition of the two of them. The in phase $v_{\mathrm{OH}}$ stretch and the out of phase $\tau_{\mathrm{OH}}$ torsion are not assigned, probably due to an overestimation of their harmonic intensity.

For other dimer conformations, the most intense $v_{\mathrm{OH}}$ stretching modes are shifted from that of the head to head homochiral. The shift amounts to $+14 \mathrm{~cm}^{-1},-61 \mathrm{~cm}^{-1}$, and $+53 \mathrm{~cm}^{-1}$ for the head to head heterochiral, the insertion, and the addition conformers, with intensity of 1342,644 , and $1027 \mathrm{~km} / \mathrm{mol}$, respectively. The MP2/AVTZ harmonic frequencies of the 4 dimer structures are gathered in Part 5 of the supplementary material. The $v_{\mathrm{OH}}$ stretch of the addition dimer could be responsible for the small band observed at $3388 \mathrm{~cm}^{-1}, 84 \mathrm{~cm}^{-1}$ higher in energy than that of the head to head homochiral. However, this conformer can be safely ruled out from energetic considerations as it is destabilized by $26 \mathrm{~kJ} / \mathrm{mol}$ relative to the most stable form. As mentioned in the experimental part, this band is probably the signature of a larger AE complex.

\section{CONCLUSIONS}

The FTIR vibrational spectra of amino-ethanol and its dimer have been recorded in jet-cooled conditions in three different regions, namely, the hydride stretch region (3250$\left.3650 \mathrm{~cm}^{-1}\right)$, the fingerprint region $\left(850-1850 \mathrm{~cm}^{-1}\right)$, and the far-IR region (150-650 $\left.\mathrm{cm}^{-1}\right)$, using the Jet-AILES apparatus at the synchrotron facility SOLEIL. These experiments confirm that the main monomer observed in jet-cooled conditions is the $\mathrm{g}^{\prime} \mathrm{Gg}^{\prime}$ form, which is responsible for all the bands observed in the hydride stretch and fingerprint regions. Less abundant conformers, namely gGt and tGt, could contribute to the room temperature spectrum in the far-IR region. Both energetic and spectroscopic criteria also show that the experimentally observed AE dimer is the head-to-head homochiral one, in which the intramolecular hydrogen bond of the monomer opens up to form a head-to-head dimer involving two strong hydrogen bonds. The transient axial chirality of the two monomers has to be synchronized for optimal interaction between them, as already observed in diols. ${ }^{46}$ The 
work conducted here also shows that correcting the harmonic frequencies calculated at the $\operatorname{CCSD}(\mathrm{T})-\mathrm{F} 12 / \mathrm{aug}-\mathrm{cc}-\mathrm{pVDZ}$ level by anharmonicity corrections arising from anharmonic calculations at the MP2/aug-cc-pVTZ level yields satisfactory results for the monomer, at an affordable calculation cost. Mode-specific scaling factors deduced from the ratio between experimental and computed frequencies for the monomers have been used for the assignment of the dimer, with a satisfactory agreement between experimental and theoretical results.

\section{SUPPLEMENTARY MATERIAL}

See supplementary material for the Cartesian coordinates, the harmonic and anharmonic frequencies computed of the four most stable conformers of aminoethanol monomer (parts 1 and 2, respectively) and dimer (parts 3 and 4, respectively), and for the NCI 3-D plots of the four most stable conformations of aminoethanol dimer (part 5).

\section{ACKNOWLEDGMENTS}

The authors are grateful to SOLEIL and the AILES staff for providing synchrotron beam under the Proposal No. 20130051. We also acknowledge the use of the computing facility cluster GMPCS of the LUMAT federation (No. FR LUMAT 2764).

${ }^{1}$ S. Steiner and G. R. Desiraju, The Weak Hydrogen Bond (Oxford University Press, Oxford, 1999).

${ }^{2}$ I. Gallou and C. H. Senanayake, Chem. Rev. 106, 2843 (2006).

${ }^{3}$ S.-I. Ishiuchi, T. Asakawa, H. Mitsuda, M. Miyazaki, S. Chakraborty, and M. Fujii, J. Phys. Chem. A 115, 10363 (2011).

${ }^{4}$ P. Butz, R. T. Kroemer, N. A. Macleod, and J. P. Simons, Phys. Chem. Chem. Phys. 4, 3566 (2002).

${ }^{5}$ A. Bouchet, J. Klyne, G. Piani, O. Dopfer, and A. Zehnacker, Phys. Chem. Chem. Phys. 17, 25809 (2015)

${ }^{6}$ A. Chakraborty, N. Guchhait, K. Le Barbu-Debus, A. Mahjoub, V. Lepère, and A. Zehnacker-Rentien, J. Phys. Chem. A 115, 9354 (2011).

${ }^{7}$ K. Le Barbu-Debus, A. Sen, M. Broquier, and A. Zehnacker, Phys. Chem. Chem. Phys. 13, 13985 (2011).

${ }^{8}$ R. Fausto, C. Cacela, and M. L. Duarte, J. Mol. Struct. 550-551, 365 (2000).

${ }^{9}$ C. F. P. Silva, M. L. T. S. Duarte, and R. Fausto, J. Mol. Struct. 482-483, 591 (1999).

${ }^{10}$ J. K. Button, K. E. Gubbins, H. Tanaka, and K. Nakanishi, Fluid Phase Equilib. 116, 320 (1996).

${ }^{11}$ M. Rasanen, A. Aspiala, and J. Murto, J. Chem. Phys. 79, 107 (1983).

${ }^{12}$ N. Seurre, K. Le Barbu-Debus, F. Lahmani, A. Zehnacker-Rentien, and J. Sepiol, J. Mol. Struct. 692, 127 (2004).

${ }^{13}$ N. Seurre, J. Sepiol, K. Le Barbu-Debus, F. Lahmani, and A. ZehnackerRentien, Phys. Chem. Chem. Phys. 6, 2867 (2004).

${ }^{14}$ N. A. Macleod and J. P. Simons, Phys. Chem. Chem. Phys. 5, 1123 (2003).

${ }^{15}$ R. E. Penn and R. F. Curl, Jr., J. Chem. Phys. 55, 651 (1971).

${ }^{16}$ M. J. Tubergen, C. R. Torok, and R. J. Lavrich, J. Chem. Phys. 119, 8397 (2003).

${ }^{17}$ S. L. Widicus, B. J. Drouin, K. A. Dyl, and G. A. Blake, J. Mol. Spectrosc. 217, 278 (2003).

${ }^{18}$ Y. Q. Liu, C. A. Rice, and M. A. Suhm, Can. J. Chem. 82, 1006 (2004).

${ }^{19}$ D. L. Thomsen, J. L. Axson, S. D. Schroder, J. R. Lane, V. Vaida, and H. G. Kjaergaard, J. Phys. Chem. A 117, 10260 (2013).

${ }^{20}$ T. D. Smith, J. B. Gerken, P. V. Jog, and J. D. Roberts, Org. Lett. 9, 4555 (2007).

${ }^{21}$ I. Vorobyov, M. C. Yappert, and D. B. DuPre, J. Phys. Chem. A 106, 668 (2002).

${ }^{22}$ L. Radom, W. A. Lathan, W. J. Hehre, and J. A. Pople, J. Am. Chem. Soc. 95, 693 (1973).

${ }^{23}$ Y. P. Chang, T. M. Su, T. W. Li, and I. Chao, J. Phys. Chem. A 101, 6107 (1997).
${ }^{24}$ G. Buemi, Int. J. Quantum Chem. 59, 227 (1996).

${ }^{25}$ K. A. Petterson, R. S. Stein, and M. D. Drake, Magn. Reson. Chem. 43, 225 (2005).

${ }^{26}$ M. Cirtog, P. Asselin, P. Soulard, B. Tremblay, B. Madebene, and M. E. Alikhani, J. Phys. Chem. A 115, 2523 (2011).

${ }^{27}$ O. Pirali, M. Goubet, T. R. Huet, R. Georges, P. Soulard, P. Asselin, J. Courbe, P. Roy, and M. Vervloet, Phys. Chem. Chem. Phys. 15, 10141 (2013).

${ }^{28}$ P. Asselin, P. Soulard, B. Madebene, M. Goubet, T. R. Huet, R. Georges, O. Pirali, and P. Roy, Phys. Chem. Chem. Phys. 16, 4797 (2014).

${ }^{29}$ T. H. Dunning, J. Chem. Phys. 90, 1007 (1989).

${ }^{30}$ R. A. Kendall, T. H. Dunning, and R. J. Harrison, J. Chem. Phys. 96, 6796 (1992).

${ }^{31}$ M. J. Frisch, G. W. Trucks, H. B. Schlegel, G. E. Scuseria, M. A. Robb, J. R. Cheeseman, G. Scalmani, V. Barone, B. Mennucci, G. A. Petersson, H. Nakatsuji, M. Caricato, X. J. Li, H. P. Hratchian, A. F. Izmaylov, J. Bloino, G. Zheng, J. L. Sonnenberg, M. Hada, M. Ehara, K. Toyota, R. Fukuda, J. Hasegawa, M. Ishida, T. Nakajima, Y. Honda, O. Kitao, H. Nakai, T. Vreven, J. J. A. Montgomery, J. E. Peralta, F. Ogliaro, M. Bearpark, J. J. Heyd, E. Brothers, K. N. Kudin, V. N. Staroverov, R. Kobayashi, J. Normand, K. Raghavachari, A. Rendell, J. C. Burant, S. S. Iyengar, J. Tomasi, M. Cossi, N. Rega, J. M. Millam, M. Klene, J. E. Knox, J. B. Cross, V. Bakken, C. Adamo, J. Jaramillo, R. Gomperts, R. E. Stratmann, O. Yazyev, A. J. Austin, R. Cammi, C. Pomelli, J. W. Ochterski, R. L. Martin, K. Morokuma, V. G. Zakrzewski, G. A. Voth, P. Salvador, J. J. Dannenberg, S. Dapprich, A. D. Daniels, O. Fark, J. B. Foresman, J. V. Ortiz, J. Cioslowski, and D. J. S. Fox, Gaussian 09, Revision E. 01, Gaussian, Inc., Wallingford, CT, 2009.

${ }^{32}$ H. J. Werner, P. J. Knowles, G. Knizia, F. R. Manby and M. Schutz, Wiley Interdiscip. Rev.: Comput. Mol. Sci. 2, 242 (2012).

${ }^{33}$ P. J. K. H.-J. Werner, G. Knizia, F. R. Manby, M. Schütz, P. Celani, T. Korona, R. Lindh, A. Mitrushenkov, G. Rauhut, K. R. Shamasundar, T. B. Adler, R. D. Amos, A. Bernhardsson, A. Berning, D. L. Cooper, M. J. O. Deegan, A. J. Dobbyn, F. Eckert, E. Goll, C. Hampel, A. Hesselmann, G. Hetzer, T. Hrenar, G. Jansen, C. Köppl, Y. Liu, A. W. Lloyd, R. A. Mata, A. J. May, S. J. McNicholas, W. Meyer, M. E. Mura, A. Nicklass, D. P. O'Neill, P. Palmieri, D. Peng, K. Pflüger, R. Pitzer, M. Reiher, T. Shiozaki, H. Stoll, A. J. Stone, R. Tarroni, T. Thorsteinsson, and M. Wang, MOLPRO, version 2012.1, a package of ab initio programs, 2012.

${ }^{34}$ J. Bloino and V. Barone, J. Chem. Phys. 136, 124108 (2012).

${ }^{35}$ R. L. Sams, S. S. Xantheas, and T. A. Blake, J. Phys. Chem. A 116, 3124 (2012).

${ }^{36}$ R. J. Plowright, E. Gloaguen, and M. Mons, ChemPhysChem 12, 1889 (2011).

${ }^{37}$ M. K. Kesharwani, B. Brauer, and J. M. L. Martin, J. Phys. Chem. A 119, 1701 (2015)

${ }^{38}$ E. R. Johnson, S. Keinan, P. Mori-Sanchez, J. Contreras-Garcia, A. J. Cohen, and W. Yang, J. Am. Chem. Soc. 132, 6498 (2010).

${ }^{39}$ J. Contreras-Garcia, W. T. Yang, and E. R. Johnson, J. Phys. Chem. A 115, 12983 (2011).

${ }^{40}$ R. Chaudret, B. D. Courcy, J. Contreras-Garcia, E. Gloaguen, A. ZehnackerRentien, M. Mons, and J. P. Piquemal, Phys. Chem. Chem. Phys. 16, 9876 (2014).

${ }^{41}$ P. L. A. Popelier and R. F. W. Bader, Chem. Phys. Lett. 189, 542 (1992).

${ }^{42}$ W. Humphrey, A. Dalke, and K. Schulten, J. Mol. Graphics 14, 33 (1996).

${ }^{43}$ B. Temelso and G. C. Shields, J. Chem. Theory Comput. 7, 2804 (2011).

${ }^{44}$ H. G. Kjaergaard, A. L. Garden, G. M. Chaban, R. B. Gerber, D. A. Matthews, and J. F. Stanton, J. Phys. Chem. A 112, 4324 (2008).

${ }^{45}$ M. Goubet, P. Soulard, O. Pirali, P. Asselin, F. Réal, S. Gruet, T. R. Huet, P. Rot, and R. Georges, Phys. Chem. Chem. Phys. 17, 7477 (2015).

${ }^{46}$ F. Kollipost, K. E. Otto, and M. A. Suhm, Angew. Chem., Int. Ed. 55, 4591 (2016).

${ }^{47}$ A. Zehnacker and M. A. Suhm, Angew. Chem., Int. Ed. 47, 6970 (2008).

${ }^{48}$ T. Scharge, C. Emmeluth, T. Häber, and M. A. Suhm, J. Mol. Struct. 786, 86 (2006).

${ }^{49}$ P. Asselin, P. Soulard, B. Madebene, M. E. Alikhani, and M. Lewerenz, Phys. Chem. Chem. Phys. 8, 1785 (2006).

${ }^{50}$ M. Broquier, F. Lahmani, A. Zehnacker-Rentien, V. Brenner, P. Millié, and A. Peremans, J. Phys. Chem. A 105, 6841 (2001).

${ }^{51}$ K. Mackeprang, H. G. Kjaergaard, T. Salmi, V. Hänninen, and L. Halonen, J. Chem. Phys. 140, 184309 (2014).

${ }^{52}$ M. Goubet, B. Madebene, and M. Lewerenz, Chimia 58, 291 (2004).

${ }^{53}$ M. Heger, M. A. Suhm, and R. A. Mata, J. Chem. Phys. 141, 101105 (2014). 